\title{
Research Identities: Reflections of a Contract Researcher
}

\author{
by Jackie Goode \\ University of Nottingham \\ Sociological Research Online, Volume 11, Issue 2, \\ < http://unw. socresonline.org.uk/11/2/goode.html> \\ doi:10.5153/sro. 1389
}

Received: 2 Feb 2006 Accepted: 13 Jun 2006 Published: 30 Jun 2006

\begin{abstract}
This paper examines the institutional identity formation of contract research staff in the context of the Taylorisation of research knowledges. The author has been a contract researcher for many years, after initially training and practising as a Probation Officer. She makes links between her social work training, and her current practice as a qualitative researcher. Drawing on her experience of working on a variety of different projects, at a number of different institutions, and providing illustrative examples from projects in sociology, social policy, health, and education, she reflects on the implications of the current social organization of academic research both for professional research practice and for researcher identity. There is a paradox in the way that contract research staff accrue a wealth of experience of how research is organised and conducted in different contexts, a repertoire of skills, and a vast volume of various kinds of 'data', whilst remaining vulnerable and marginalized figures within the academy, with few opportunities for professional development and advancement. She outlines a number of strategies she has employed in the preservation of the 'research self', and concludes by suggesting that the academy has much to learn about the effective management of 'waste', as embodied by researchers' selves and their data, consequent upon the Taylorisation of research work.
\end{abstract}

\section{Keywords: Taylorisation; Academic Work; Identities; Qualitative Research; In- Depth Interviews; Reflective Practice}

\section{Introduction}

1.1 All major social change brings with it both 'winners' and losers'. This is certainly the case in relation to changes in the labour market in general, and in the organisation of academic work in particular. In this context, I would characterize Contract Researchers, as a group, as amongst the 'losers'. The impact the Taylorisation of academic work (Marginson, 2000; Schapper and Mayson, 2004) has had on contract researchers is both quantitative and qualitative. Morgan et al (2000) document a particularly marked growth in the use of fixed-term contracts in recent years in the public services in general, in universities in particular, and especially in relation to research workers and to women (see also Bryson and Tulle-Winton; Bryson, 1999, 2000); whilst contract researchers themselves attest to the fact that their contractual status within the labour market is highly significant for their identity (Crawshaw, 1985; Newbury, 1995; Hockey, 2004). In this paper, I use my own experiences as a contract researcher to reflect on various aspects of institutional identity construction, including, but not confined to, those arising from the inherent 'mobility' of contract researchers.

1.2 The fate of contract research staff (CRS) is to move from project to project, and sometimes from institution to institution, in order to stay employed. Those of us who have managed to do this for any length of time have perforce accrued a wealth of experience of how research is organised and conducted in different contexts, a repertoire of skills, and a vast volume of data, some of which never see the light of day, but which we 'carry' with us (physically, quite often, as well as metaphorically). Academic staff engaged in qualitative research, as well as CRS, will be familiar with the acquisition of this kind of material, but the whole process of deploying one's self in co-producing such data, living with/'swimming in' it on a day-to-day basis, analysing, interpreting, selecting from, and shaping it for various audiences, does not define their professional identity in quite the same way. The contract researcher is permanently engaged in deploying her/his self to create intimate relationships which by their very nature are 'meaningful', before moving on to a new project with a new set of colleagues and research 'subjects'. 'The project' constitutes its own bounded social world within which meaning is constructed, and CRS are required to parcel that 'meaningfulness' up 
and leave it, and to re-create themselves anew in another arena. They have constantly to negotiate a series of beginnings and endings, and there is always a 'residue' of 'data', always unfinished business. Of some significance for me is the fact that I have had other professional identities on which to draw. After qualifying and practising for periods of time as both a Probation Officer and a teacher, I took up full-time academic research in 1992, since when I have worked at four different institutions, on ten different funded projects, each lasting between six months and two years. In all cases, I had primary responsibility for the qualitative fieldwork, data analysis, writing, and publishing. In my research practice, I have drawn heavily on my early 1970s psychoanalytic/psychodynamic social work training, and this informs some of my reflections here.

1.3 As Coffey (1999) observes, 'fieldwork involves the enactment of social roles and responsibilities which place the self at the heart of the enterprise' (p23), and I consider first the identity work that takes place 'without' the institution, that is, 'in the field'. Here, I draw on Fine's (1993) 'ten lies of ethnography', the 'illusions [that are] essential to maintain an occupational reputation' (p267). Secondly, I consider identity work that is undertaken within the institution, arising out of the ways in which the contract researcher is positioned structurally, and out of the institutional negotiations that take place. Finally, I examine identity work arising out of the researcher's moves between projects and institutions.

1.4 Richardson (1992) comments that 'Like other cultural groups, academics fail to recognise their practices as cultural/political choices, much less see how they are personally affected by those practices....Although there are textually marginal places, such as appendices and prefaces, for social scientists to ponder their lived experience, making that experience the centerpiece of an article seems Improper, bordering on the Gauche and Burdensome' (p126). I hope, like her, not to venture beyond Improper, as I reflect on the identity work that the contract researcher is subject to and has to do on her/himself in order to construct and keep her/his professional identity intact. Like Sikes (2006), I don't regard identities as fixed entities, but as 'forged, rehearsed and remade' (Lee \& Bould, 2003:188) through discursive practices and social interactions, and it is these practices and interactions that are the subject of my reflections.

\section{'Extra-institutional' identity work}

2.1 My aim here is to examine identity work arising out of the researcher's relationships and interactions with 'subjects' in the field, and the 'data' these produce. In order to do so, I need to say something about what constitutes data for me, because it will explain why I refer to an ethnographic approach as opposed simply to 'interview-based research', and because it introduces the emotional labour (Hochschild, 1983) undertaken by the researcher which contributes to her/his identity as a kind of 'repository' or 'carrier' of 'data', as much as one of analyst. Whilst all the projects I have worked on have used in-depth interviewing, many have also included quantitative data collection and analysis, documentary analysis, observation (both participant and non-participant) over extended periods of time, and audio and video recordings of interactions. It is not the use of a 'family of methods' (Willis and Trondman, 2000) alone which encourages me to talk of ethnography, however, but also how I conceptualise the in-depth interview. The kinds of ethnographic data that are co-produced within that space outside of and around the hour or so of the 'formal' interview, as well as within it, for example, the telephone calls to make the arrangements, the social exchanges upon arrival, the considered explanations about the nature of the project and the questions these might provoke, the discussions of ethical issues such as confidentiality and informed consent, the creation of 'rapport', and the interactions at the point of departure - all of these are too often regarded, in interview-based studies, as what Delamont et al (2000:51) refer to as a 'residue to be eliminated' rather than as an intrinsic and important feature of all knowledge production - and, I am arguing here, identity construction.

2.2 Perhaps it is my social work training that has led me always to see the in-depth interview in these terms, as a series of mini-encounters, adding up to a whole 'interactional event', rather than as confined to what ends up on the tape. In challenging the 'lie' of the 'unobtrusive ethnographer', Fine (ibid) confesses: 'Over time, I have chosen...to recognize my participatory desires. Although I still attempt not to put too fast a spin on a setting, I add myself to the mix, and I attempt to understand how I feel as a participant'. 'Kleinman (1991)', he goes on, 'made us recognize that our emotions, as they arise in field settings, directly influence what we see, how we get along with others, and the strategic choices that we make in our ethnographies' (p281). Following the rallying cry of social work trainers in the '60s/'70s to recognise that 'feelings are facts!' and the work of feminist researchers who made it legitimate to do so, I have always 'added myself to the mix'. In 'the field' of social work practice, we were specifically taught to pay attention to how clients made us feel (angry, sad, maternal, guilty, powerless etc), and to analyse these feelings as well as 'surface' data, for what they told us about both the client and ourselves as practitioners (a point later made by Kleinman and Copp, 1993: viii, in relation to research). Further, accepting that we wouldn't necessarily like all our clients, (another of the 'classic virtues' Fine aims to explode), and that they might mislead, evade, lie and 'put up fronts' - and overriding our own negative feelings, because we still owed them 
a duty of care ('befriending' being an official part of the role of Probation Officers then), was part of learning to be a 'professional'. But in the field of research, it was as late as 1996, at the Fourth International Social Science Methodology Conference at Essex, before many researchers had their first opportunity to discuss 'The Emotional Nature of Qualitative Research' with colleagues (Bourne, 1998).

2.3 We were also taught the significance of the 'openings' of first encounters with clients, and to give thought to the sometimes tacit and sometimes overt 'contract' both parties were entering into, which in those long-gone days of 'voluntarism', even for Probation clients, would be a 'therapeutic' version of the legal one they had entered into with the court when being sentenced. This 'treatment model' of Probation supervision may have subsequently fallen into disrepute for effectively 'pathologising' low tariff offenders, and the parameters of contracts between researchers and 'subjects' are certainly different to those between social workers and clients, but the concept of 'informed consent', as well as how it might be negotiated, were familiar to me when I changed careers. We were taught too to recognise the importance of the 'closings' of interviews, which might feature that familiar phenomenon of learning what was really the most important issue for the client only as they were half way out the door; and how to 'manage' difficult or burdensome issues and emotions that had been opened up, sometimes by enabling clients, and ourselves, safely to 'contain' them until a later time or setting. I was aware, as a beginning researcher, of the differences between the researcher role and that of 'counsellor', and I do my own 'boundary work' along the line between research interviewing and 'therapy'. The latter is not part of the implicit contract that has been signed up to by research participants, even if they do on occasion exert their own agency to utilise the encounter in this way (the interview sometimes acting to give 'ceremonial permission' (Hochschild, 1983: 68), to men in particular, to disclose pain and vulnerability). Unlike a counsellor, however, I am not going to be around to 'pick up the pieces' if revelations leave interviewees feeling vulnerable and exposed in ways that they had not anticipated, and this has meant sometimes steering people away from making disclosures, no matter how 'juicy' they promised to be. I was taken aback on one occasion by hearing a sociologist of sport tell, in his presentation, of the sexual abuse by their coaches that had been disclosed to him by interviewees - with no apparent sense of what his obligations might be in that situation. We carry a responsibility for what we hear, and some shared 'secrets', as well as having legal implications, call for more than an 'uncontaminated' research response.

2.4 Despite the intrinsic differences between the two fields, however, there is much common ground: formulating and asking open questions; 'active listening'; 'reflecting back' what people have said in order to encourage them to expand on it further, or to check my interpretation of it; 'following their lead' whilst still covering my topic guide; the simultaneous collection and analysis of data in an iterative process; and the treatment of transcript data in a number of different ways, for example, as 'information', but also as 'interaction', as 'talk' that is 'doing' something, and telling us things in the doing - this way of understanding talk having been learnt through guided analysis of numerous transcripts of social work interviews, an approach which left us in no doubt that the interview as interaction is a 'joint production'.

2.5 What has not been 'transferred' is the system of supervision built in to social work agencies, in those days as a support mechanism as much as one of surveillance and control. If we found ourselves as 'repositories' of 'data' (information, accounts, powerful emotions - clients' or our own), regular supervision sessions with one's 'Senior' ('line manager' in current parlance) were designed to help us manage these effectively, and to support our continuing professional development. The fact that such a system does not form part of the social organisation of academic research means that the researcher can end up carrying 'stuff', that is in effect defined as 'extraneous', around with her/him.

2.6 A number of examples from my own practice, of being confronted with unexpected and therefore shocking eventualities, illustrate this. On a 'sociology of food and eating' project, I arrived at the doorstep to discover that my interviewee was a woman of my own age who was paraplegic and severely speechimpaired as a result of a road accident. She was unable to eat 'ordinary' food. It turned out that she had loved food before her accident - choosing it, cooking it, eating it, entertaining. On a project studying a telephone health information and advice service, I interviewed callers. There was no way of knowing the outcomes of individual calls beforehand, and I arrived for one interview to discover that my interviewee's baby, the 'subject' of her call to the service, had subsequently and very recently died. On a project studying the intra-household distribution of income by families in receipt of benefits, I interviewed a young father who was in constant pain due to a back injury suffered as a roofer. He feared that he may never work again, and he disclosed how ashamed he felt that he was no longer able properly to provide for his wife and family. On a study of the use of Problem Based Learning on a new medical course, I did an interview with a GP/facilitator. In telling me a story about being "torn to shreds" by a colleague to whom he had gone for advice and support, his sense of being brought low and made to feel incompetent was palpable. All of these people were keen to do the interview, so what was 'difficult'? Both the handling of the 'interactional practicalities' (getting my 'ear in' sufficiently to understand the speech-impaired interviewee; handling the young mother's distress as she recounted the story of her baby's death; responding appropriately to the 
young man's need to pause from time to time to cope with the pain he was in, and to the GP now reduced to a cowed and deflated self), and my own emotional responses - to the overwhelming loss each of these people had suffered; to my sense of anger on behalf of the GP whom I had earlier observed in animated action, getting on famously with his student-group, clearly enjoying his work; to (the transference of) his pain to me, reflected in my physical response, after he left the room, of feeling as though I had been hit in the solar plexus and left winded by the blow to 'self' that he had sustained; to my recognition of the fragility of life, and to the fear engendered by the apparent 'arbitrariness' of such losses - none of which I had been able to prepare for, and none of which found their way into any of the project reports, not because they were not illuminating, but because there was no natural 'space' within those projects for them to be represented. One has to do some 'repair work' to one's professional and personal self as a result of such experiences, which can occur on any qualitative research project, not just those explicitly dealing with 'sensitive topics', because in-depth interviews are by definition intimate human encounters.

2.7 A different kind of repair work sometimes has to be done when interviewing 'elites', this time to one's own self-esteem and sense of competence. To some extent, the balance of power rests with the researcher regardless of how 'non-directive' s/he is in an interview, but I have had control of the interview summarily wrested from me by both politicians and members of the professoriat. 'Reputation' featuring prominently in the careers of both, they are adept at 'presentations of the self'. Whilst not true of all of those I interviewed, there were certainly some from both groups who were highly status conscious, who valued their time much more highly than mine, who were unabashed at drastically cutting short the time they had agreed to give after I had travelled a long way to see them, who gave me little chance to set the agenda, and who consciously or otherwise, were just patronising. I have also had research 'rubbished' prior to its entering the public domain, on methodological grounds, (in one case by having an ethnographic approach characterized as a gratuitous 'fishing expedition' with no clear 'hypotheses', and in another, by having its validity queried because the data consisted of 'only' forty in-depth interviews, producing no evidence of 'what works'), by senior personnel who were in fact ideologically opposed to the 'findings'.

2.8 The fair interpretation and the publicising of research results becomes increasingly complex as the numbers of 'stakeholders' increase. Researchers sometimes have to withstand assaults on their professional identity despite trying to follow good practice, and without, as Barbour (1998) remarks, much practical guidance on choosing examples for our oral, written (and visual) presentations. In a project studying the experiences of students with disabilities, student-guided videoing was undertaken - events were filmed which had previously presented obstacles to access for them. I selected clips from this footage, and reviewed them individually with those appearing in them. This was to validate my interpretation of them, to add a taped student 'commentary' on them in the training materials for which they had been planned, and to secure further consent to show them alongside presentations of the written project report to various university committees. Despite going through this process, however, one committee member expressed misgivings about two clips: one showing a wheelchair user on her way to lectures, being forced to travel along a road in between parked cars and oncoming traffic, because drop-down kerbs were not aligned, and another showing a blind student being unintentionally excluded by her fellow students from a small group seminar discussion. The committee member's reservations were about what he called representations of 'heroic victimhood'. As I had been aware of this concept from the literature, and as what was captured in the clips had been directed by the students themselves, whose representations had the stronger claim? I did not feel that I had represented my interviewees as heroic victims, and read the committee member's response not only as a concern not to stereotype student experience, but also as a discursive strategy aimed at managing demand in the larger 'battle' for scarce resources between disabled students and university. The contract researcher can feel very vulnerable and 'exposed' when on the receiving end of such confrontations whilst 'in the field' or presenting her/his work.

2.9 However, as Fine (ibid) observes, by treating all encounters such as those outlined above as data, there is sometimes a possibility of 'turning the tables' on those who exert their power to 'subvert' the research, as long as one is careful to exclude identifying features - as he did when writing about a baseball coach who had 'humiliated' him (p274), and as I did (Goode, 1998) on a project looking at gender relations in the academy, by writing about the irony of the way a male professor had taken control of the interview before I had even had chance to speak, in order to employ various strategies to demonstrate his 'gender credentials' to me before allowing me to start, and who had then rather let himself down by telling me both how he had actively promoted the selection and advancement of an "attractive young" female academic, and how much trouble he had in managing "menopausal women" technical staff who "whinged" too much - a double whammy of sexism and ageism. Especially when conducting research in one's own institution, as that was, experience of status and power can undergo a number of changes, contributing to shifting constructions of researcher identity. I turn now to other intra-institutional relations that contribute to identity construction. 
3.1 In most workplaces there are institutional markers of employee status, and the academy is no exception. As elsewhere, the most obvious ones are job title and salary. The Taylorisation of research work means that CRS salaries are usually dependent on grades fixed by funding bodies, and this often leads to anomalies amongst CRS working on different projects even within the same institution and department. What the implications are for CRS careers of the recently introduced 'full economic costings' of research proposals remains to be seen, but there may be some risk that this will further disadvantage more experienced, more 'expensive' researchers, if applicants look for ways of bringing overall costs in beneath a perceived ceiling. Anomalies exist in relation to job titles too, in my experience, with no clear and consistent practice within and between institutions in relation to the use of 'Research Assistant' and 'Research Fellow'. Room allocations are another common marker of status, with jokes abounding (which are sometimes not too far from the truth) about CRS working out of cupboards. For example, when the team I was working with was relocated to another building, my 'academic' colleagues were allocated a room each, and I was - temporarily I was assured - allocated a 'hot desk' space in the room shared by a large number of research students. Would this have been offered to an academic colleague? And how would they have reacted? I chose to work from home until allocated at least a room shared with another member of the research staff (only academic staff are allowed a room of their own), which I was then given - after a short stay in a vacant professorial room (large rooms, lake-views), which raised a few eyebrows. In the face of these anomalies, I have increasingly consciously constructed, presented, and worked to maintain a researcher identity for myself which is not dependent upon my 'structural' position within the institution. A 'fluidity' of status can be exploited, as colleagues don't always know how to place research staff. I have found that the more one behaves as having equal status with whoever one is interacting with (within limits), by 'displaying one's cultural capital', the more one is viewed and treated as such. And in terms of gaining access to resources (information, opportunities etc) the 'constructed' identity can override the 'official' one. In this way identities are 'established in the response' as Rolling (2004: 876) puts it.

3.2 Of course one has to accrue some cultural capital in the first place, and this can be a tricky business, which once again depends to some extent on the power relations between the various staff on research projects. Pls usually have organisational seniority, but the level of 'hands on' involvement they have in the research itself can vary enormously. CRS similarly can be recruited specifically to undertake particular components of the research, or to carry primary responsibility for the execution and completion of the whole project (and sometimes they can be recruited for the former and end up doing the latter). There may therefore be further anomalies in the relationships between where they, PIs and co-applicants are located. There is very often a gap between the rhetoric of research being conducted in 'teams,' and the realities of work undertaken by CRS, with other team members making different kinds of contributions, which can be as little (quantitatively, though not qualitatively) as lending their name to proposals for funding. Where Pls also share some aspects of data analysis, project priorities usually preclude any sharing of those 'tales of the field' (Van Manaan, 1988) that are painful for both participants and fieldworker. The paradox is that the researcher who does most of the 'physical' labour (and fieldwork is definitely physical, as well as emotional and intellectual labour) becomes disembodied. Further, in practice, lines of accountability usually only go in an 'upward' direction, despite the co-dependence of team members for its success. There are anomalies too for CRS in the degree to which they can participate in post-project outputs when they are employed fulltime by another grant-holder at another institution. Power-relations between project researchers themselves are therefore context-specific and shifting, and the 'rewards' in terms of cultural capital can be incommensurate with the work undertaken.

3.3 Barry et al (1999) have written about how the use of reflexivity as a research team activity can improve the productivity and functioning of qualitative teams and the rigour and quality of the research, and I have certainly experienced this. For example, as I was making an early progress report to the Advisory Group for the project studying the distribution of household income within families receiving benefits, observations were made about the apparent readiness and ease with which some interviewees had disclosed normally private and sensitive information about their finances and family lives. Whilst this may have been a product of sensitive ethnography, it is also possible, as another member of the Advisory Group suggested, that interviewees' behaviour in this respect signalled that this was only the latest occasion, as individuals subject to state regulation in fairly intrusive ways, on which they had been asked to 'tell their story' to a 'public official'. This interpretation highlighted the importance of recognising the power of the state to render open for public scrutiny for some groups, what is for the rest of us private. It also revealed the value of collaborative research teams for bringing multiple perspectives to bear on research data.

3.4 But collaboration between colleagues on research projects is not always straightforward. Barry et al (ibid) quote Delaney and Ames:

How do people from different disciplines, professionally socialized in graduate school not to share, begin the process of opening up in order to participate in the fashioning of better information products? (1993: 8) 
3.5 Epistemological differences within disciplines, never mind between them, can also have implications for researcher identity. I have given an account of how I see the in-depth interview, but discussion of what status is being accorded these data is very rare. An exception was when I collaborated recently on a project that involved both in-depth interviewing, and Conversation Analysis of telephone interactions, the latter undertaken by a colleague. And then I bristled slightly at my colleague's depiction of 'my' data as 'contextual material' to support the 'core' CA data. Whilst I appreciated that epistemological issues are involved in combining different kinds of data, and understood the importance for a 'CA person' of protecting his academic reputation in the relatively small world of purists who argue that nothing outside 'the text' is of any significance, it felt like an attack on my identity as a skilled practitioner capable of producing 'high quality data' of worth in its own right. The fact that the issue of combining these two kinds of data was never fully resolved, on a funded project which brought all the attendant pressures of delivering 'outcomes' on time, perhaps constitutes another 'lie' to add to Fine's list - that of 'mixed methods' being the new orthodoxy, at least as far as common understandings of how the mixing can/should be done are concerned.

3.6 Another issue which may not be explicitly addressed in teams is that of intellectual property. As Barry et al (ibid) observe, authorship is consistently one of the most contentious aspects of collaborative work. They followed Erickson and Stull's (1998) advice to draw up a team contract, with issues of data ownership and publication policy decided before the fieldwork begins. That is very difficult for CRS to initiate, although I began routinely to seek explicit clarification of projects' 'policies' on these issues after one particularly negative experience. On a project in which I was responsible for the research design, all the fieldwork, data analysis, writing, and (joint) publication, (but not for securing the funding, which was obtained by a group of permanent academic staff), sections of a document I had written were appropriated verbatim, after the project had ended and I had moved on, by a senior colleague who published as sole author, without even acknowledging my 'contribution'. After discovering the article by chance, I emailed the author asking for an explanation, but received no reply. More common, as I became more familiar with academic conventions and what constituted career capital, and more able to be assertive even with senior colleagues, was being first author on papers I had written. But the prized single-authored papers have come primarily from work done over and above, and after, writing an acceptable number of papers that are, by convention, jointly authored, regardless of the differential contributions that have been made by team members. Erickson and Stull suggest that: "Top down writing may not provide the best representation of people's ideas but it is the most efficient" (p49). My own experience, even on the efficiency argument, would not confirm this. My identity as a 'good' researcher, insofar as this is based on publication track record, has been hard fought and hard won. And because it has arisen from 'contract-hopping', it has made for an 'unconventional' CV. I turn now to the inter-institutional construction of researcher identity, beginning with its crucial representation at the job application and interview stage.

\section{Inter-institutional identity work}

4.1 Writing about the sometimes 'dodgy ground' on which researchers work, Sikes (2006) comments: 'Ideally people work on research which, in all its dimensions, accords with their beliefs and values and which matches their philosophical position/s with regard to ontology, epistemology and human nature and agency. When this happens, researchers can believe in what they are doing and maintain their integrity. They are able to be the sort of researcher/academic they want to be and be seen as being. They are doing research that supports their own 'identity work' (Coffey, 1999) ... unfortunately, such congruence is not always achieved...' (p207). As she acknowledges, 'pressing financial and familial commitments' mean that we aren't always able to choose what accords most closely with our own interests and values (although, despite having research interests of my own, of which more later, I do become very interested in whatever I am researching at the time - an example, perhaps, of Stronach et al's (1996)'Mother of Invention Making Virtue out of Necessity').

4.2 As revealed earlier, trying to build a 'research career' as well as avoiding breaks in employment, has meant, for me, moving from one project and one institution to another. I have done this at the same time as fulfilling a commitment to home and children which has limited my mobility. I am proud of the fact that I have managed to achieve continuous employment as an academic researcher for the last fourteen years, but there are serious implications for the labourer's work identity of a system which relies on insecure waged labour. Planning ahead, getting a mortgage, and the implications for one's pension have been significant examples. It is also a costly path to tread in terms of one's sense of one's own integrity. And I am using 'integrity' here both in the 'moral' sense (of making the sort of research compromises we all have to make in the new academic order), and in the sense of keeping one's self intact. It is hard, for example, to go from naively believing, as a novice, the rhetoric about how much universities value not only research but the researchers who produce it, to, some years later, dealing in a 'grown up' way with a Head of Department's 'jokes' about there being 'plenty more at the factory gate' when my imminent redundancy threatened. If the efficient management of 'waste' is a necessary feature of Taylorist labour processes, it is painful to find oneself defined as waste that can so easily be disposed of. One has to reconstruct oneself 
anew in order to secure the next project, at another institution, with a new set of colleagues, and this is especially hard if it involves slipping a few rungs down the salary scale on a project whose timescale does not offer any opportunity to clamber back up to one's former level. There is an inherent tension for CRS between a continuous sense of the research self, and institutional and substantive discontinuities between projects, research topics and research sites. As this pattern continues, one also has to construct one's 'codified self', as represented by the $\mathrm{CV}$, as having some semblance of coherence, and some demonstrable relevance for the next post.

4.3 Even when one is successful in this, one's skills and accumulated knowledge may not be recognised or valued. At one institution, I was invited at the last minute (the PI apologised for forgetting to invite me earlier) to the departmental Christmas dinner, and as I chatted on the way into the restaurant with a member of staff I had not met before, he asked me questions about who I was and what I was doing, the answers to which necessitated partial revelation of my 'background'. 'Ah', he said in disparaging tones, 'so you're a kind of jobbing researcher'. That was me labelled and dismissed. A lawyer with a record of mastering new briefs quickly and efficiently, and consistently 'producing the goods' would not be described thus, but despite the rhetoric about the value of 'transferable skills', it is increasing specialisation that is valued in academia, and CRS who find themselves on the transfer list. At an interview at another institution, a professor queried my 'interesting' CV, asking why it (I) was such a 'hybrid'. There were so many possible answers to this, but I risked a smiling 'Because I'm a woman'. I was rewarded by a responsive laugh of appreciation from the one woman on the panel, whose own smile at her professorial colleague had more than a hint of challenge in it. And I got the job.

4.4 If more conventional rewards like salary, security, status, esteem and advancement are lacking, how can CRS shore up their fragile identities as 'professional' researchers? In particular contexts, (including the selection interview referred to above) I have identified qualitative methodologies as a continuous strand in my own work, and claimed these as my specialism. But my research identity has also been positively reinforced by the sociologist, now retired, with whom I worked on one of my earliest projects. She has become an invaluable and much appreciated mentor, and it is with her that I have had my most stimulating and educative theoretical and methodological discussions. It was she too who suggested one day, when I was bemoaning my lack of success at the time in securing funding in my own right, and finding myself yet again working on others' research agendas, that I turn to what I enjoyed most outside of work as a subject for research. She can take much credit, therefore, for the fact that I did so, conducting fieldwork, analysis, and writing, in my own time, taking annual leave to accept an invitation to present at my first ever international conference, and acquiring my first two single authored publications (Goode, 2002; 2006). These particular activities are unlikely to count as 'career capital' as they don't 'fit in' with my institutional identity. They represent another anomaly, another 'discontinuity'. But they were not 'jobbing research', and in allowing me to follow my own interests and genuinely to 'speak in my own voice', they have contributed more to my own sense of my research self than much of what I have achieved 'within' the academy.

\section{Discussion/Conclusion: the institutional construction of researcher identity}

5.1 Much writing on CRS has tended to concentrate, with good cause, on their structural position within academia, and their contractual arrangements. What has received less attention is what researchers 'do' with the accumulations of the kinds of experiences recounted here, and how they contribute to processes of occupational socialisation and identity construction (Wellin and Fine, 2001). I have used reflections on my experiences as a contract researcher to do several things: to examine the institutional construction of research identities; to identify some of the sources upon which I draw in my professional practice; and to draw attention to some of the 'data' that often get excluded from these settings, by paying attention to the personal, emotional and identity dimensions of undertaking fieldwork on projects at different academic institutions. I have shown how the researcher can become the repository of different kinds of data (painful respondent stories) to those which s/he perhaps anticipated collecting, and the dilemmas of knowing what to 'do' with such data. More often than not, they are 'held' by the researcher, and carried away to the next project, or else reflected upon in something of a vacuum.

5.2 Despite using many of the skills I learnt from social work training and practice, the kind of stories I have referred to are part and parcel of research projects, not of other kinds of social relations. In her classic text on feminist interviewing, Oakley (1982) argues for a minimsing of social distance between (female) research 'subject' and (feminist) researcher. I am more concerned with maintaining appropriate boundaries. I recognise the existence of Lofland's 'two worlds', and the need that Hammersley identifies, to maintain a distance between those two worlds:

While research involves a process of mediation between the 'worlds' of the people being studied and the 'world' of the researcher, this process requires the maintenance of distance as well as contact: it requires the researcher to move conceptually backwards and forwards, nearer and then further away. Lofland talks of the way the ethnographer needs to operate in 
two worlds (Lofland, 1972: 97, 108-9). He also reports a sense of betrayal because, however much the ethnographer may appear to participants to have joined 'their world', he or she remains located in the 'world' of the research, a 'world' which has different priorities from theirs. This is also a reason why researchers cannot avoid those they study often reacting against the accounts provided in research reports. (Hammersley, 2002: 74)

5.3 One of the skills of the 'professional' researcher is to manage these dynamics effectively. But where does consideration of these dynamics and the shifting ground upon which identities are constructed figure within the management of research projects? The BSA's ethical guidelines include sections on responsibilities towards the profession, towards 'participants' and towards 'funders', but nothing on what might constitute ethical relations between research colleagues. The institutional model of research underpinning the guidelines is an individualised one. It implicitly confirms Fine's (ibid) characterisation of researchers as 'lone rangers, cowboys, individualists' (p269). I see this as a gendered characterisation; as Barry et al showed, it need not be a lone occupation, and teamwork can optimise the efficacy of the research. But some questions remain. What role should PIs play, for example, when the professional integrity of a contract researcher is challenged by 'elite' respondents? Or when the researcher needs to 'offload' emotionally? Unlike earlier models of social work organisation, academic research offers no official systems or spaces in which stories, secrets, 'lies', 'betrayals' and emotional responses are accorded the status they deserve, either as an intrinsic feature of knowledge production, or as constitutive of researcher identity. Researchers, and 'marginalised' CRS in particular, can experience 'emotional exile' (Bourne, 1998: p99). CRS may, like one of Tommy Cooper's famous stage acts ${ }^{[1]}$, become adept at putting on and taking off a series of hats, as they move between 'field relations' and 'project relations'; between project relations and wider institutional relations; and between one institution and another. But in this ongoing project of identity production and maintenance, they are more often than not reliant on themselves successfully to negotiate research identities that will prove robust enough to stay the course.

5.4 The Taylorisation of research knowledges affects more than institutional forms of self-governance. The fragmentation resulting from the intellectual division of labour the process entails, and the kinds of social relations engendered as a consequence, also have implications for the construction of research identities. The process may be appropriated at different levels of intensity and sincerity by the research self. Cooley (1981) predicted that the increased productivity of academic workers 'could have consequences much more widespread and subtle than the obvious ones of increased work tempo, loss of control, job insecurity and even redundancy. The impact it will have on the creativity of those involved is likely to be significant...' (p52). If I have on occasion felt 'exploited' by finding myself carrying responsibility for a 'whole project' (apart from its original conception), from 'operationalisation' to publication, I have also had more of the creative and intellectual satisfaction of following the process through from beginning to end, and less of the alienation that fragmentation can bring. But the academy has a lot to learn about how to manage 'waste', as embodied by researchers' selves and their data, efficiently and effectively. The latest Framework Agreement on the 'modernisation of pay structures' in HE requires notice to be taken of the Fixed Term Employees (Prevention of Less Favourable Treatments) Regulations 2002, due to take full effect from July 2006. These give new protection for CRS, by conferring a right to a permanent contract after four years continuous service (which commenced after 10 July 2002), if at least one contract extension has been granted. This will offer enhanced continuity and security for some staff, but it remains to be seen how a let-out clause about providing 'objective reasons' to justify continuing use of a fixed-term contract is interpreted by different HEls. Before this measure came in, I had found for myself an invaluable resource in the person of an academic 'mentor'. She has provided me with support for the preservation and development of my professional identity that has often been institutionally lacking. She also encouraged me to undertake research that is truly 'mine', which helped me achieve those first sole-authored papers. Unfortunately, in 'career capital' terms, they too are 'extraneous' to my 'official' identity. But 'jobbing researchers' can always exploit, if they are astute, having yet another string to their bow.

\section{Acknowledgements}

I would like to thank the three anonymous referees of this article for their very helpful comments and suggestions, and to express my gratitude to my friend and mentor Teresa Keil for all her generous support.

\section{Notes}

${ }^{1}$ Tommy Cooper was one of Britain's best loved comics and magicians, recognized by his trademark 'fez' and catch-phrase 'Just like that!' He worked long and hard to perfect the tricks and gags that were a feature of a stage show characterized by apparent incompetence. One of his acts involved a series of hilarious quick changes of character, using only a succession of hats from a 'props' box. 


\section{References}

BARBOUR, R. S. (1998) Engagement, representation and presentation in research practice. In Rosaline S. Barbour and Guro Huby (eds) Meddling with Mythology. Routledge, London.

BARRY, C.A., Britten, N., Barber, N., Bradley, C., and Stevenson, F. (1999) Using Reflexivity to Optimize Teamwork in Qualitative Research. Qualitative Health Research Vol.9, No.1, 26-44

BOURNE, J. (1998) Researchers experience emotions too. In Rosaline S. Barbour and Guro Huby (eds) Meddling with Mythology. Routledge, London.

BRYSON, C., and Tulle-Winton, E. (1994) A survey of contract research staff in UK universities . London: AUT.

BRYSON, C. (1999) Contract research: the failure to address the real issues. Higher Education Review , 31 (2): $29-49$

BRYSON, C. (2000) The casualisation of employment in higher education in the United Kingdom. In, Academic Work and Life: what it is to be an academic and how this is changing (ed) Malcolm Tight. JAI/Elsevier Science, London.

COFFEY, A. (1999) The ethnographic self: fieldwork and the representation of identity . London: SAGE, 1999

COOLEY, M. (1981) The Taylorization of Intellectual Work. In Levidow, L. and Young B. (eds) Science, technology and the labour process CSE Books, London.

CRAWSHAW, B. (1985) Contract research, the university, and the academic. Higher Education, 14, 665682

DELANEY, W., and Ames, G. (1993) Integration and exchange in multidisciplinary alcohol research. Social Science \& Medicine, 37, 5-13

DELAMONT S., Atkinson, P., and Parry, O. (2000) The Doctoral Experience, Success and Failure in Graduate School. Falmer press, London and New York.

ERICKSON, K.C., and Stull, D. D. (1998) Doing Team Ethnography: Warnings and advice. Qualitative Research Methods Series, Vol.42. Thousand Oaks, CA: Sage.

FINE, G.A. (1993) Ten Lies of Ethnography: Moral Dilemmas of Field research. Journal of Contemporary Ethnography, Vol.22, No.3, 267-294

GOODE, J. and Bagilhole, B. (1998) The Social Construction of Gendered Equal Opportunities in UK Universities: A Case Study of Women Technicians. Critical Social Policy, Vol 18 (2) pp175-192.

GOODE, Jackie (2002) Collecting Time: the social organisation of collecting, in Social Conceptions of Time: Structure and process in Work and Everyday Life (eds) Sue Heath and Graham Crow. Palgrave.

GOODE, Jackie. (forthcoming 2006) Moving On: Overlooked Aspects of Modern Collecting. In Laurence Fontaine (ed) Alternative Exchanges: Second-hand Circulations from the Sixteenth Century to the Present . Marcel van der Linden 'International Studies in Social History' series, Berghahn Publishers, Oxford.

HAMMERSLEY, M (2002) Educational Research, Policymaking and Practice . London: Paul Chapman.

HOCHSCHILD, A. R. (1983) The managed heart: commercialization of human feeling . Berkeley: University of California Press.

HOCKEY, J. (2004) Working to return to employment: the case of UK social science contract researchers. Studies in Higher Education, Volume 29, Number 5: 559-574

KLEINMAN, S. (1991) Fieldworkers' feelings: what we feel, who we are, how we analyze. In Experiencing fieldwork (eds) W.B. Shaffir and R.A. Stebbins, 184-95. Newbury Park SA: Sage.

KLEINMAN, S. and Copp, A. (1993) Emotions and Fieldwork, Thousand Oaks, CA: Sage.

LEE, A. \& Boud, D. (2003) Writing groups, change and academic identity: research development as local practice. Studies in Higher Education 28(2) 187-200 
LOFLAND, J. (1972) Analyzing Social Settings. Belmont, CA, Wadsworth.

MARGINSON, S. (2000) Rethinking academic work in the global era. Journal of Higher Education Policy and Management 22, 23-35

MORGAN, P., Allington, L. and Heery, E. (2000) Employment Insecurity in the public services, in Heery, E., and Salmon. J. (eds) The Insecure Workforce. Routledge, London and New York.

NEWBURY, D. (1995) A journey in research, from research assistant to Doctor of Philosophy. Journal of Graduate Education 2, 2, 53-59

OAKLEY, A. (1982) Interviewing Women: A Contradiction in terms. In H. Roberts (ed) Doing Feminist Research. London: Routledge.

RICHARDSON, L. (1992) The Consequences of Poetic Representation, Writing the Other; Rewriting the Self. In Carolyn Ellis and Michael G. Flaherty (eds) Investigating Subjectivity, Research on Lived Experience. Sage, London.

ROLLING, J. (2004) Searching self-image: identities to be self-evident. Qualitative Inquiry 10(6) 869-884

SCHAPPER, J.M. and Mayson, S.E. (2004) Internationalisation of Curricula: An alternative to the Taylorisation of academic work. Journal of Higher Education Policy and Management Vol.26, No.2, pp189205

STRONACH, I., Allan, J., and Morris, B. (1996) Can the Mothers of Invention Make Virtue out of Necessity? An optimistic deconstruction of research compromises in contract research and evaluation. British Educational Research Journal, Vol.22, No.4, pp493-509

SIKES, P. (2006) On dodgy ground? Problematics and ethics in educational research. International Journal of Research \& Method in Education Vol.29, No.1, 105-117

VAN MAANEN, J. (1988) Tales of the Field: On Writing Ethnography. University of Chicago Press, Chicago.

WELLIN, C., and Fine, G.A. (2001) Ethnography as Work: Career Socialization, Settings and problems. In Atkinson et al (eds) Handbook of Ethnography, Sage: London.

WILLIS, P. and Trondman, M. (2000) Manifesto for ethnography. Ethnography 1 (1): 5-16. 